\title{
Sustainability Index for the Management of River Basins Based Upon Ecological, Environmental and Hydrological Integrity and the Minimization of Long Term Risks to Supply
}

\author{
Robert L. Oxley ${ }^{1} \&$ Larry W. Mays ${ }^{1}$ \\ ${ }^{1}$ School of Sustainable Engineering and the Built Environment, Arizona State University, Tempe, AZ \\ Correspondence: Larry W. Mays, School of Sustainable Engineering and the Built Environment, Arizona State \\ University, Tempe, AZ. E-mail: mays@asu.edu
}

Received: February 25, 2017

Accepted: May 9, 2017

Online Published: October 16, 2017

doi:10.5539/enrr.v7n4p1

URL: https://doi.org/10.5539/enrr.v7n4p1

\begin{abstract}
A new methodology for determining a sustainability index (SI) for the management of river basins is developed. Sustainability is defined in terms of minimizing the long-term risks to supply and maintaining the ecological, environmental and hydrological integrity of a river resource. The SI procedure developed uses two groups of performance criteria. The first group is based on demand-supply deficits and measures the risk to water supplies. The second group is only applied to river demands and compares a river's allocation to a target flow regime using the Range of Variability Approach (RVA) and the Modified Hydrological Alteration factor. The RVA measures differences in flow regimes and is used to compare a projected flow regime to a targeted flow regime. This is the first attempt to use the RVA to develop a sustainability index for river basin management. A combined sustainability metric for the system (SS) is also determined. The methodology is applied to an area including the Prescott Active Management Area (AMA) in north-central Arizona. Sustainability for the entire system is determined using the weighted sum of the sustainability indices. The methodology has been used to measure and compare the sustainability of two allocation scenarios for the Prescott AMA.
\end{abstract}

Keywords: river basin management, sustainability, range of variability approach, modified hydrologic alteration factor, sustainability index

\section{Introduction}

\subsection{Objective}

Water stress is a reality for a large portion of the world's population (Alcamo et al., 2007; Rijsberman, 2006; Rosegrant et al., 2002; Vorosmarty, 2000). Recently, the dependency of riverine ecological systems on flow regimes has been recognized (Arthington et al., 2006; Poff 2009; Poff et al., 1997) and concern over ecosystem degradation adds to the challenges of river basin management. The questions at hand are: how do managers meet immediate water demands while ensuring water availability for future needs? And, how are established societal needs balanced with the increasing awareness that human society is reliant upon a water dependent ecological system? Mays (2007) defined water resources sustainability as "the ability to use water in sufficient quantities and quality from the local to the global scale to meet the needs of humans and ecosystems for the present and the future to sustain life and to protect humans from the dangers brought about by natural and human-caused disasters that affect sustaining life."

The objective of this study is the development of a sustainability index (SI) for river basin management based upon ecological, environmental and hydrological integrity in addition to demand-supply deficit based performance criteria. The SI methodology discussed herein has been applied by Oxley, Mays, and Murray (2016) and Oxley and Mays (2016) for the optimal allocation of water for a river basin management area.

\subsection{Sustainability for Water Resources Management}

The concept of sustainability gained traction after the Brundtland Report (World Commission on Environment and Development, 1987) and discussions on definition and applications followed. In general terms, sustainability is often associated with environmental concerns, long term availability and use patterns. In this context, the concept of sustainability would seem to be especially suited to answer the water management questions raised in the 
preceding paragraph. Despite the prominence and appeal of the sustainability concept, translating the current definitions and principals into practical application remains problematic (Gleick, 2000; Kuhlman \& Farrington, 2010; Lant, 2007; Loucks, 1997; Loucks et al., 1999; Solow, 1993; Unver, 2007).

Applications introducing the concepts of sustainability in water resources management optimization models have been previously developed by Rothman (2007) and Rothman and Mays (2014). The use of sustainability in an optimization model for water resources planning and management was introduced by Cai (1999) and Cai et al., (2003). Sustainability in water resources can be measured using the concept of a sustainability index (SI) (Loucks, 1997; Sandoval-Solis et al., 2011; Aydin et al., 2014a and b; and Mays, 2013). These previous applications have ranged from water supply management to water distribution system sustainability to groundwater management.

Oxley, Mays, and Murray (2016) presented a new methodology for the sustainable and optimal allocation of water for a river basin management area. The model distinguishes between short and long-term planning horizons and goals using a short-term modeling component (STM) and a long-term modeling component (LTM) respectively. The STM is a linear programming problem, and optimizes a monthly allocation schedule on an annual basis in terms of maximum net economic benefit. An LTM consists of an STM for every year of the long-term planning horizon. Each LTM is quantified using a sustainability index, with the approach discussed in this paper. The LTMs are optimized to determine the most sustainable net economic benefit for the management area using a genetic algorithm. Oxley and Mays (2016) applied this model to the Prescott Active Management Area (Prescott AMA), a management area in north-central Arizona experiencing rapid population growth and limited water resources. The methodology for determining sustainability indices developed by Oxley (2015) and used in Oxley, Mays, and Murray (2016) and Oxley and Mays (2016) is described in this paper with an application to the Prescott AMA.

Sustainability requires the identification, pursuit and protection of societal objectives and ecosystem integrity. Though by no means comprehensive, societal objectives can be examined and then expressed as demands. Likewise, ecological, environmental and hydrological integrity can be expressed as demands within the system if a means of determining the demand and measuring the adequacy of both the demand and supply are available. Ecological research suggests that this is best addressed using the concept of the flow regime.

\section{Definitions}

The SI procedure developed in this research (Oxley, 2015) uses two groups of performance criteria. The first group uses demand-supply deficit based performance criteria and measures the risk to water supplies. The second group is only applied to river demands and compares a river's allocation to a target flow regime using the range of variability approach (RVA). The performance criteria are applied to a long-term allocation schedule. Sustainability for the entire system (SS) is determined using a combination of the SIs.

\subsection{Flow Regimes}

A river's flow regime is described using a record of daily flows. The target flow regime is supplied by the user. This requires a daily-flow (each 24 hours) record spanning one or more years. To ease computational burden, a monthly flow demand is determined by summing the daily flow values in the target regime for each respective month:

$$
d_{j, t}=\sum_{\text {day }}^{\text {Day }} \text { DailyFlow } w_{j, t, \text { day }}^{\text {Target }}
$$

where $d_{j, t}$ is the monthly demand and DailyFlow $w_{j, t, \text { day }}^{\text {Target }}$ is the daily flow value for demand node $j$, and day day, belonging to month $t$.

The projected flow regime is derived from the volume allocated to meet the river's monthly flow demand. The volume allocated, or monthly flow supplied to a river, is based upon an available monthly flow supply. To generate an available monthly flow supply, the available daily flow supply is summed over each respective month. This becomes the monthly input for a river's source node:

$$
\text { source_input }_{i, t}=\sum_{\text {day }}^{\text {Day }} \text { DailyFlow } \text { Available }_{\text {day }}
$$

where source_input ${ }_{i, t}$ is the monthly input and DailyFlow Available is the daily flow value for source node $i$, and day day, belonging to month $t$. The volume at source_input $t_{i, t}$ is available for monthly allocation to a river.

After the monthly flow supply is allocated, the projected flow regime is computed by first determining the daily flow value for the projected flow regime by calculating the difference between the monthly demand and monthly supply: 


$$
\text { MonthlyDifference }_{j, t}=d_{j, t}-\sum_{i}^{I} x_{i, j, t}
$$

where MonthlyDifference ${ }_{i, t}$ is the difference between the demand and allocated supply, $d_{j, t}$ is the monthly demand and $x_{i, j, t}$ is the supply for source node $i$, demand node $j$, during month $t$. MonthlyDifference $e_{i, t}$ is in turn used as the basis for determining the projected daily flows:

$$
\text { AveDailyDif } f_{j, t}=\frac{\text { MonthlyDifference }_{j, t}}{30.42}
$$

where AveDailyDif $f_{j, t, d a y}$ is the average flow difference per day for demand node $j$, and month $t$. The denominator is in units of [days per year]/[months per year]. The projected daily flow is calculated as:

$$
\text { DailyFlow }_{j, t, d}^{\text {Projected }}=\text { DailyFlow }_{j, t, \text { day }}^{\text {Target }}-\text { AveDailyDif }_{j, t}
$$

where DailyFlow $w_{j, t, d}^{\text {Projected }}$ is the daily projected flow for demand node $j$, and day day, belonging to month $t$. Conceptually, this is similar to a decrease in base flow for a river. The target and projected flow regimes may be compared using the RVA.

\section{Range of Variability Approach (RVA) for Assessing Flow Regimes}

Of the approaches developed for assessing flow regimes, the RVA is by far the most prevalent and widely used in the science of environmental flow assessment (Tharme, 2003). The RVA was developed in Richter et al. (1997) in response to the need to determine how much flow alteration was 'too much' and attempts to provide a comprehensive statistical characterization of ecologically relevant flow regime features.

Table 1. IHA Index values used in the developed model

\begin{tabular}{clll}
\hline Index & \multicolumn{1}{c}{ IHA } & Index & \multicolumn{1}{c}{ IHA } \\
\hline 1 & Median flow for month 1 & 17 & 90-day minimum \\
2 & Median Flow for month 2 & 18 & 1-day maximum \\
3 & Median flow for month 3 & 19 & 3-day maximum \\
4 & Median flow for month 4 & 20 & 7-day maximum \\
5 & Median flow for month 5 & 21 & 30-day maximum \\
6 & Median flow for month 6 & 22 & 90-day maximum \\
7 & Median flow for month 7 & 23 & Number of zero days \\
8 & Median flow for month 8 & 24 & Base flow index \\
9 & Median flow for month 9 & 25 & Date of minimum \\
10 & Median flow for month 10 & 26 & Date of maximum \\
11 & Median flow for month 11 & 27 & Low pulse count \\
12 & Median flow for month 12 & 28 & Low pulse duration \\
13 & 1-day minimum & 29 & High pulse count \\
14 & 3-day minimum & 30 & High pulse duration \\
15 & 7-day minimum & 31 & Rise rate \\
16 & 30-day minimum & 32 & Fall rate \\
& & 33 & Number of reversals \\
\hline
\end{tabular}

\subsection{Indicators of Hydrologic Alteration (IHA)}

The RVA uses the pre-impact natural variation of 33 Indicators of Hydrologic Alteration (IHA) parameter values derived from long-term daily flow records as a basis for measuring and defining the extent to which a flow regime has changed post-development (see Table 1). The IHA parameters were selected based upon two primary criteria: ecological relevance (particularly their use in published ecological studies as described by Tharme (2003)) and an ability to reflect a broad range of human induced changes. The IHAs are grouped in one of five parameter groups: magnitude of monthly water conditions; magnitude and duration of annual extreme water conditions; timing of 
annual extreme water conditions; frequency and duration of high and low pulses; and rate and frequency of water condition changes (The Nature Conservancy, 2009).

To perform the RVA, flow data is separated into pre- and post-impact respective to the 'time of impact' (generally corresponding with some man-made change to the river). IHAs are independently calculated for each data set. The IHAs are further divided into three equal bins based upon either percentile values (for non-parametric analysis) or some number of standard deviations from the mean (parametric analysis), making for a total of 99 IHA parameter values. The observed IHA occurrences from the pre-impact period become the expected occurrences for the postimpact period with:

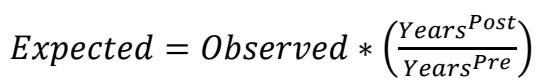

where Years $^{\text {Post }}$ and Years ${ }^{\text {Pre }}$ are the number of years in the post- and pre-impact datasets respectively. This process is depicted graphically in Figures 1 and 2. The change to the flow regime is expressed in terms of a series of Hydrologic Alteration (HA) factors which are calculated as:

$$
H A=\frac{(\text { observed-Expected })}{\text { Expected }}
$$

A positive HA value indicates an increase in the frequency of the respective IHA values from the pre- to postimpact years (maximum value of infinity), while a negative value indicates a decrease in the relative occurrences (minimum value of negative one). An HA value of zero signifies no change. A modified HA is developed and used in this research.

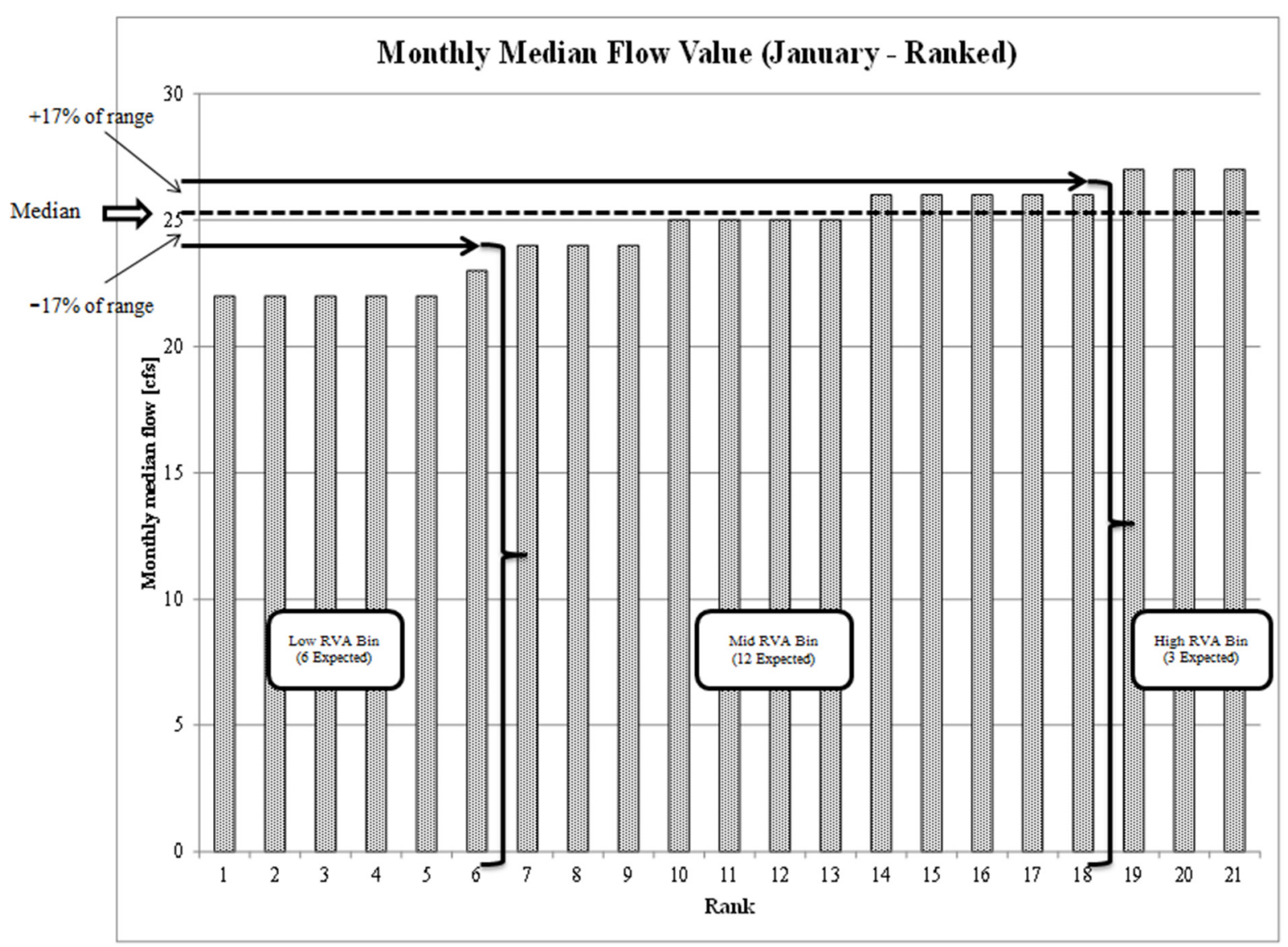

Figure 1. Example of non-parametric bin delineation on the pre-impact time period and expected values 


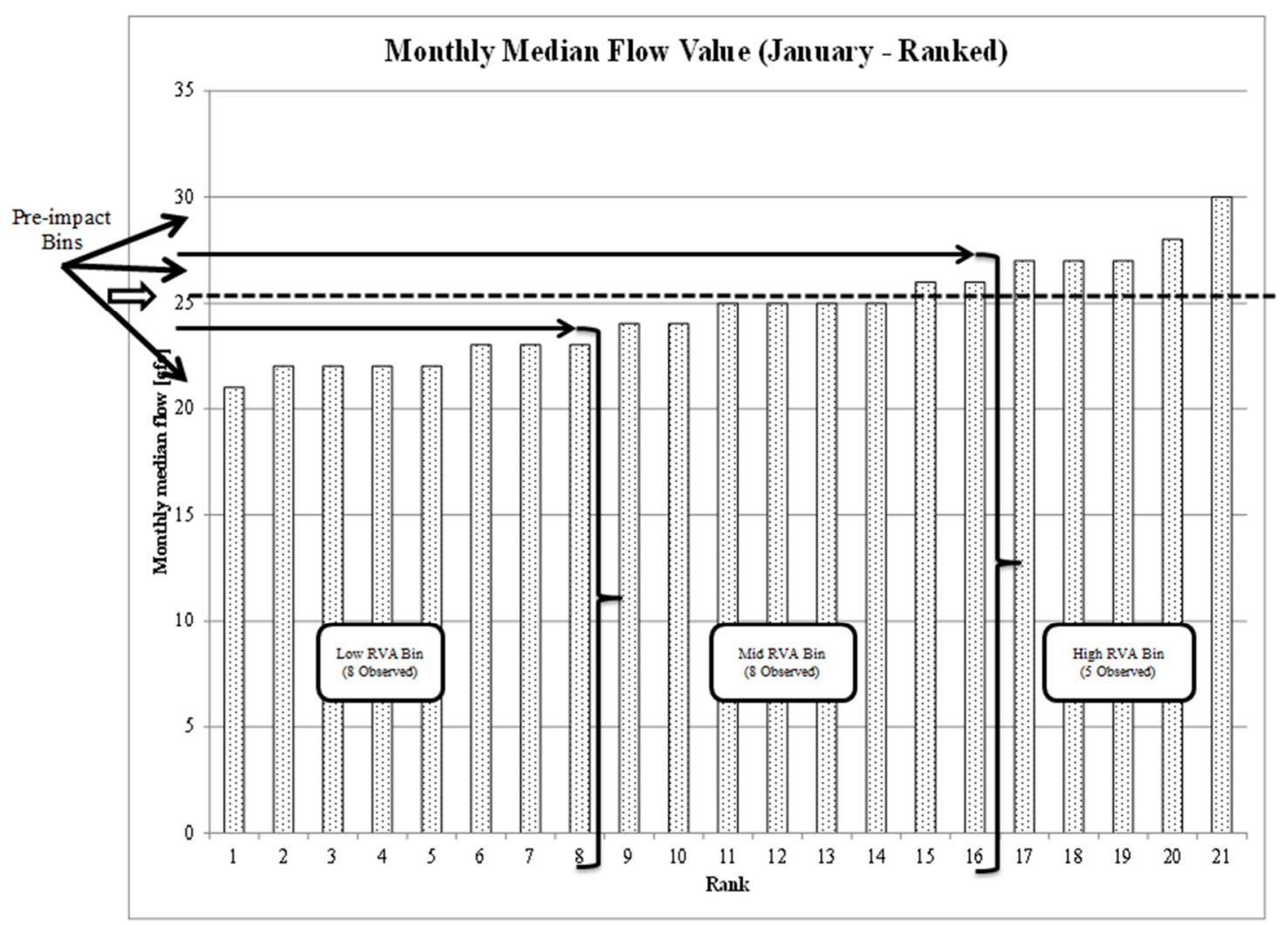

Figure 2. Example of non-parametric bin assignments for the post-impact time period and observed values

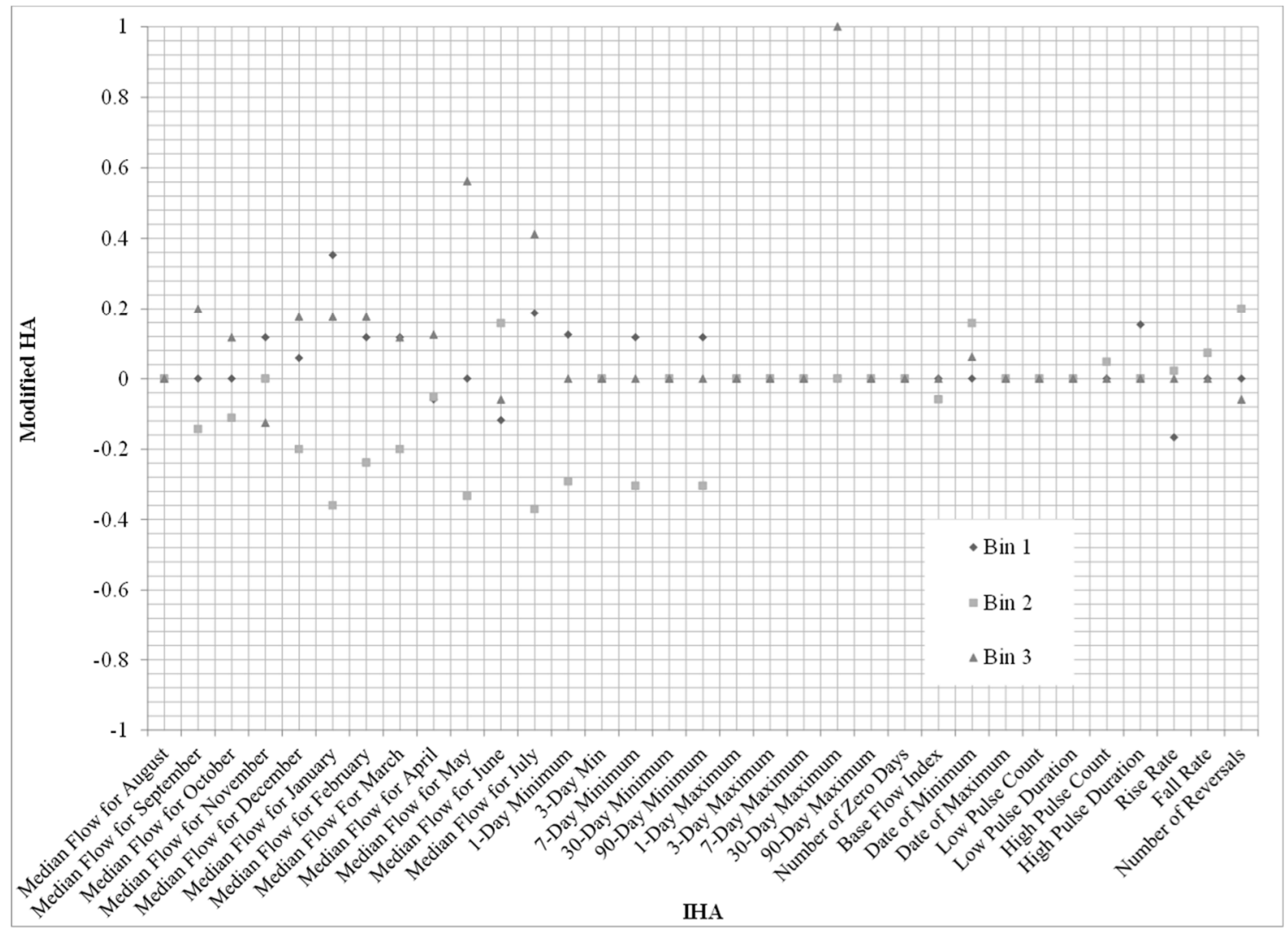

Figure 3. Example modified HA values 


\subsection{Modified Hydrologic Alteration HA}

The RVA is being used in this application to compare a 'projected flow regime', which is the flow regime projected by the model, to a 'target' or ecologically sound flow regime using a Modified HA value. This concept is introduced here as performance criteria for the SI with applicable nomenclature. The 'observed' IHA values from the target flow regime become the 'expected' IHA values in the projected flow regime dependent upon the number of years being used as the basis for each regime:

$$
\text { Expected }_{\text {Bin,IHA }}^{\text {Projected }}=\text { Observed }_{\text {Bin,IHA }}^{\text {Target }} *\left(\frac{\text { Years }^{\text {Projected }}}{\text { Years }^{\text {Target }}}\right)
$$

where Expected $_{\text {Bin,IHA }}^{\text {Projected }}$ refers to the IHA values for the projected flow regime; Observed Bin,IHA $_{\text {Target }}$ refers to the IHA values for the target flow regime, Bin is the bin index (1 through 3) (see Figures 1 and 2); IHA is the IHA index (1 through 33); and Years ${ }^{\text {Projected }}$ and Years ${ }^{\text {Target }}$ are the number of years being used as the basis for the projected and target flow regimes respectively.

As discussed previously, the IHA values for each regime are typically compared using a degree of Hydrologic Alteration (HA), reiterated here with appropriate subscripts as:

$$
H A_{B i n, I H A}=\frac{\left(\text { observed }_{\text {Bin,IHA }}^{\text {Projected }}-\text { Expected }_{\text {Bin, }, H A}^{\text {Projected }}\right)}{\text { Expected }_{\text {Bin, }, H A}^{\text {Projected }}}
$$

where $H A_{B i n, I H A}$ is the HA value, Observed Pin,IHA $_{\text {Projed }}$ is the IHA occurrence in the projected flow regime and Expected $_{B i n, I H A}^{\text {Projected }}$ is the expected IHA occurrence for bin Bin and IHA index IHA. Values for the HA range from -1 to infinity, with 0 representing no difference between the target and projected flow regimes. It is noted that positive values signify more observed values than expected values, and for this application, it is assumed that values greater than 1 do not necessarily require more attention than the most negative value. Under this assumption, the HA has been modified $\left(H A_{B i n, I H A}^{M O d}\right)$ for this research as:

$$
\begin{aligned}
& \frac{\left(\text { Observed }_{\text {Bin,IHA }}^{\text {Projected }}-\text { Expected }_{\text {Bin,IHA }}^{\text {Projected }}\right)}{\text { Observed }} \\
& H A_{B i n, I H A}^{M o d}= \\
& \frac{\left(\text { observed }_{\text {Bin,IHA }}^{\text {Projected }}-\text { Expected }_{\text {Bin,IHA }}^{\text {Projected }}\right)}{\text { Expected }_{\text {Bin,IHA }}^{\text {Projected }}} \\
& \begin{array}{l}
\text { (if } \text { Expected }_{\text {Bin,IHA }}^{\text {Projected }}< \\
\text { Observed }_{\text {Bin,IHA }}^{\text {Project }} \text { ) }
\end{array} \\
& \text { (if } \text { Expected }_{\text {Bin,IHA }}^{\text {Projected }}> \\
& \text { Observed }_{\text {Bin,IHA }}^{\text {Project }} \text { ) }
\end{aligned}
$$

where $H A_{B i n, I H A}^{M o d}$ is the Modified HA value, Observed Pin,IHA $_{\text {Projted }}$ is the IHA value in the projected flow regime and Expected Ein,IHA $_{\text {Projed }}$ is the IHA value in the projected flow regime for bin Bin and IHA index IHA. $H A_{B i n, I H A}^{M o d}$ ranges from -1 to 1 , with 0 still representative of no differences between the target and projected flow regimes.

\subsection{Interpretation of the Modified IHA}

The following summarizes how the Modified HA is calculated and how the output may be interpreted. As discussed previously, the Modified HA is measuring the observed occurrences of an IHA value (projected flow) against the expected occurrences of an IHA value (target flow) and that zero signifies no difference between the projected and target flows.

Recalling the adopted terminology, the target flow regime refers to the river's demand, or the ecologically sound (assumed) flow regime; while the projected flow regime refers to the flow regime that is a result of the volume allocated to the river. A negative value indicates that the occurrences in the target flow (Expected) are more than the occurrences in the projected flow (Observed). A positive value indicates that the occurrences in the target flow (Expected) are fewer than the occurrences in the projected flow (Observed).

As indicated earlier, the RVA preserves extreme IHA values by distributing the values among three bins. The bins are defined using the range of IHA values discovered in the target flow, the range is divided equally into three bins, and each of the IHA occurrences are assigned accordingly. As an example, consider the Median Flow in 
April IHA. Assume that the Median Flow in April ranges from $18 \mathrm{cfs}$ to $41 \mathrm{cfs}$ in the target flow. The bin thresholds would be established as:

$$
\text { Thresholds }=29.5[c f s] \pm 23[c f s] * 0.17
$$

where 29.5 is the median value, $23 \mathrm{cfs}$ is the range, and $17 \%$ is one-half of $33 \%$ (rounded up). The assignments are as:

$$
\begin{aligned}
& \text { Median Flow in April }<25.6[c f s]=\text { Bin } 1 \\
& 25.6[c f s] \leq \text { Median Flow in April } \leq 33.4[c f s]=\text { Bin } 2 \\
& \text { Median Flow in April }>33.4[c f s]=\text { Bin } 3
\end{aligned}
$$

Each occurrence of the Median Flow in April in the target flow is assigned to a bin, which then become the Expected value of occurrences. Each value of the median flow in April discovered in the projected flow is assigned to a bin (using the same thresholds), and becomes one of the Observed occurrences. When Expected occurrences are more than the Observed occurrences, the $H A_{B i n, I H A}^{M o d}$ will be negative. When Observed occurrences are more

\begin{tabular}{|c|c|c|c|c|}
\hline Bin & Value & Cause & Observation & Practical Interpretation \\
\hline \multirow{2}{*}{1} & Positive & Observed $>$ Expected & $\begin{array}{l}\text { The projected flow has more IHAs with } \\
\text { lower values }\end{array}$ & $\begin{array}{l}\text { IHAs in projected flow tend to be lower than } \\
\text { target flow IHAs }\end{array}$ \\
\hline & Negative & Observed $<$ Expected & $\begin{array}{l}\text { The projected flow has fewer IHAs with } \\
\text { lower values }\end{array}$ & $\begin{array}{l}\text { IHAs in the projected flow tend to be higher } \\
\text { than target flow IHAs }\end{array}$ \\
\hline \multirow{2}{*}{2} & Positive & Observed $>$ Expected & $\begin{array}{l}\text { The projected flow has more IHAs with } \\
\text { median values }\end{array}$ & - \\
\hline & Negative & Observed $<$ Expected & $\begin{array}{l}\text { The projected flow has fewer IHAs with } \\
\text { median values }\end{array}$ & - \\
\hline \multirow{2}{*}{3} & Positive & Observed $>$ Expected & $\begin{array}{l}\text { The projected flow has more IHAs with } \\
\text { higher values }\end{array}$ & $\begin{array}{l}\text { IHAs in projected flow tend to be higher } \\
\text { than target flow IHAs }\end{array}$ \\
\hline & Negative & Observed $<$ Expected & $\begin{array}{l}\text { The projected flow has fewer IHAs with } \\
\text { higher values }\end{array}$ & $\begin{array}{l}\text { IHAs in the projected flow tend to be lower } \\
\text { than target flow IHAs }\end{array}$ \\
\hline
\end{tabular}
than Expected occurrences, the value of $H A_{B i n, I H A}^{M O d}$ will be positive. General characterizations of the projected flow are listed in Table 2.

Table 2. General characterizations of the projected flow using the modified HA.

The application in this research uses an annual daily schedule of flows for the target flow. A single year of daily flows produces only one value for each of the IHA metrics. In this case, the Bins have a threshold of the discovered value \pm 0 . Understanding this permits an interpretation of the sample Modified HA data presented in Figure 3. For example, the median flow in January has a modified HA value of -0.4 in Bin 2 . This suggests that the median flow in January in the projected flow was not the median flow in January value discovered in the target flow. It does not however suggest that the median flow in January is smaller in magnitude in the modeled value than in the target flow. To discover this, the Modified HA value in Bins 1 and 3 are referred to: Bin 1 has a Median Flow in January of approximately 0.35 while Bin 3 has a value of approximately 0.17 . This indicates that the median flow in January value occurs more frequently in Bin 1 than it does in Bin 3. As the denominator remains the same (Observed $>$ Expected), it can be said that the frequency of occurrence in Bin 1 is twice that of Bin 3; or that the Median Flow in January for the modeled flow is less than the value in the target flow twice as often as it is higher; suggesting a deficit in January for most of the modeled flow regime. The same method may be applied to the remaining IHAs for a general characterization of the deficiencies in the projected flow regime.

The prior discussion is unique to the one-year target regime. In practical application, a target regime encompassing several years of daily flows would allow more variance $H A_{B i n, I H A}^{M o d}$ in the projected flows by widening the bin delineations. The following discussion uses the as a set of performance criteria in the SI.

\section{Computation of Sustainability Index (SI)}

\subsection{Sustainability Index (SI)}

Sustainability can be measured by the sustainability index SI: 


$$
S I_{g, j}=\left[\prod_{m}^{M} C_{g, m, j}\right]^{1 / M}
$$

where $C_{g, m, j}$ is performance criterion $m$ belonging to sustainability group $g$ and demand $j$. As described, the SI ranges from 0 to 1 with a value of 1 indicating maximum sustainability.

The performance criteria in this application are divided into two groups. The first group measures the risk associated with a demand's supply and is based on demand-supply deficits. The second group measures the integrity of a river's regime and uses the Modified HA $\left(H A_{B i n, I H A}^{M O d}\right)$. Each demand is assigned to a sustainability group $(g)$ based upon performance criteria applicability. For example, flow regime criteria are not applicable to non-river flow demands.

\subsection{Demand-Supply Deficit}

Demands in sustainability group $1(g=1)$ are assessed with the demand-supply deficit based criteria:

$$
D e f_{j, t}=d_{j, t}-\sum_{i}^{I} x_{i, j, t}
$$

where $D e f_{j, t}$ is the deficit and $d_{j, t}$ is the demand for source $j$ in month $t$; and $x_{\mathrm{i}, j, t}$ is the volume water supplied demand for source $i$, demand $j$ in month $t$. Deficits are positive when a demand is not fully realized for the $j^{t h}$ demand and equal to zero when the water supplied is equal to the demand $\left(\sum_{i}^{I} x_{i, j, t}=d_{j, t}\right)$. The deficit based performance criteria are calculated over the length of the long-term time horizon for each demand and include reliability, resilience, maximum vulnerability, and maximum deficit.

\subsection{Reliability, Resilience, Vulnerability, and Maximum Deficit}

Reliability is concerned with the number of times a demand has been fully supplied. Reliability for demand $j$ and month $t$ is defined as:

$$
C_{1,1, j}=\operatorname{Rel}_{j}=\frac{\# \text { of times Def }_{y, j, t}=0}{T}
$$

where $T$ is the total number of months.

Resilience is a measure of system recovery after a failure to meet demand:

$$
C_{1,2, j}=\text { Res }_{j}=\frac{\# \text { of times Def } j, t=0 \text { follows Def } f_{j, t}>0}{\text { No.of times Def } f_{j, t}>0 \text { occurred }}
$$

Maximum vulnerability is defined as the most severe of the system's failures to meet monthly demand:

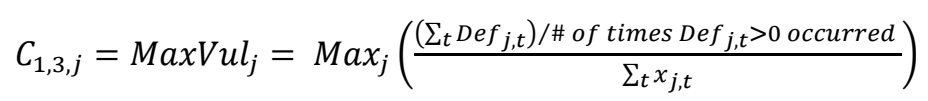

The last performance criterion is concerned with the maximum deficit, which is defined as the most severe case of failure to meet demand:

$$
C_{1,4, j}=\operatorname{MaxD}_{j}=\operatorname{Max}_{j}\left(\frac{\sum_{t} D e f_{j, t}}{\sum_{t} d_{j, t}}\right)
$$

For demands in the system that are susceptible to demand-supply deficits $(g=1)$, the SI is expressed as:

$$
S I_{1, j}=\left[\operatorname{Rel}_{j} * \operatorname{Res}_{j} *\left(1-\operatorname{MaxVul}_{j}\right) *\left(1-\operatorname{Max}_{j}\right)\right]^{1 / 4}
$$

The second set of performance criteria $(g=2)$ is based upon the differences between a target and projected flow regime as measured by the Modified HA. The SI calculation associated with these criteria is conditional based upon the value of the Modified HA:

$$
S I_{2, j}=\begin{array}{ll}
\prod_{I H A} \prod_{\text {Bin }}\left[\left(1-H A_{j, I H A, B i n}^{\text {ood }}\right)\right]^{1 / 99} & H A_{j, I H A, \text { Bin }}^{\text {Mod }} \geq 0 \\
\prod_{I H A} \prod_{\text {Bin }}\left[\left(1+H A_{j, I H A, B \text { in }}^{\text {Mod }}\right)\right]^{1 / 99} & H A_{j, I H A, \text { Bin }}^{\text {Mod }}<0
\end{array}
$$

\section{System Sustainability}

The sustainability of a system (SS) is calculated as the sum of the weighted sustainability indexes: 


$$
S S=\sum_{g} \sum_{j} v_{g, j} * S I_{g, j}
$$

where $v_{g, j}$ is the relative weight for the $j$ th water user in sustainability group $g$ and ranges from zero to one and sums to one:

$$
\sum_{g} \sum_{j} v_{g, j}=1
$$

The potential weighting options include 1) a weighting based on water demand; 2) and arithmetic average or equalattribute-based weighting system; 3) explicit weights based on a) utility theory analysis, principal components analysis, or hedonic model according to regression coefficients; or b) based on expert and professional opinion. Determining which of these is case dependent and subjective. Principal component analysis determines weighting based on the variance of the SI, this invokes the normality assumption of theoretical statistics and utilizes the overall variance of the data matrix. The hedonic approach regresses upon variables against selected instrumental variable(s) and weights the variables per the regression coefficients (Slottje 1991).

\section{Application of Approach to Prescott Active Management Area (AMA)}

Application of the methodology was performed using the Prescott Active Management Area (AMA) in northcentral Arizona (see Figure 4). The Arizona AMAs are a management concept pursuant to the 1980 Arizona Groundwater Management Code, created to address severe ground water overdraft within the state. Five AMAs were established in Arizona, covering the areas of most severe overdraft with boundaries generally determined by groundwater basins and sub-basins (Arizona Department of Water Resources (n.d.).

\subsection{Description of Study Area}

The largest municipality in the Prescott AMA is the Town of Prescott, which is located in central Arizona and home to approximately forty-thousand people (U.S. Census Bureau 2010). The populations of Prescott and the surrounding area have enjoyed rapid growth over the last several years as more people become aware of the many benefits of residing in the area. As is often the case, rapid growth has placed undue pressure on the surrounding ecosystem and available natural resources that support the population, most notably, on the very limited water supply. In response to declining aquifer levels and regulatory compliance deadlines, the Town of Prescott has developed a plan to pump and transport water from the Big Chino aquifer, a location outside of the Prescott AMA (see Figure 4) and AMA regulation. This plan has generated a lot of controversy as the ecological and economic impacts of the pumping are beginning to be understood. A recent study completed by the United States Geological Survey (USGS) (Pool et al., 2011) suggests that pumping in the proposed location would significantly impact the flows of the Verde River, a primary source of water for the City of Phoenix.

\subsection{Scenarios}

Two population growth and consumption rate scenarios (see Tables 3 and 4) for the Prescott AMA are simulated and impacts to the sustainability of the system are compared as an example application. A schematic of the physical system and adaptation for the application is presented in Figure 5 with demand and source-node labels indicated in Tables 5 and 6. Each of the sources for the zones are described as independent source nodes with independent links for each source to the demand within the model but are pictured as composites in the schematic. Demand and supply are expressed for each month $(t)$ for 50 years $(T=600)$. Residential demand is calculated as a linear function of consumption rate and residential population (consumers) and fulfilled at the expense of other demands in the system. Agricultural and industrial demands are assumed to be static. As demand is supplied from available source nodes, supply at the source changes as:

$$
s_{i, t}=s_{i, t-1}-\sum_{j} x_{i, j, t}
$$

Where $s_{i, t}$ is the supply available at source node $i$ during month $t$, and $x_{i, j, t}$ is the volume supplied from source node $i$, to demand node $j$ during month $t$. Physical parameters for the scenarios include initial residential population, population growth and consumption rates, aquifer storage levels, historical river flow data, a linear aquifer response function and infrastructure capacities.

Historical daily flow data is used as the Verde River supply basis and projected demands. Daily flows are summed to determine a monthly flow and monthly deficits are used as the basis for an average daily deficit. River supply is modified by an aquifer response function:

$$
x_{9,16, t}=\text { source }_{\text {input }_{9, t}}-0.0104 * \Delta s_{1, t}
$$

Where $x_{9,16, t}$ is the allocated supply from source node 9 (Verde River source), demand node 16 (Verde River), source $_{\text {input }_{9, t}}$ is the monthly input at source node 9 (Verde River source) based on the historical flow data and $\Delta s_{1, t}$ is the change in storage at source node 1 (Big Chino), for month $t$. The coefficient is in units of $m o n t h^{-1}$ 
and based upon data derived from an area groundwater model (Pool et al., 2011). The change in storage at source node 1 (Big Chino) is defined as:

$$
\Delta s_{1, t}=s_{1,0}-s_{1, t}
$$

where $s_{1,0}$ is the initial storage volume and $s_{1, t}$ is the storage volume for source node 1 (Big Chino) and month $t$.

A comparison of the SS values for each of the scenarios is presented in Table 7 with the demand-based performance criteria $(\boldsymbol{g}=\mathbf{1})$. SI values for each demand node is depicted in Figure 6 . Scenario 2 has a slightly higher value of SS, suggesting that this scenario is more sustainable than Scenario 1 . Both scenarios see decreased sustainability on demand nodes 6 and 11 (Zone 1 - Chino Valley agricultural and industrial demands respectively) and a minimum SI on the Verde River (demand node 16). Figure 7 shows the ratio of annual supply to demand on the Verde River in percent.

The ratio of monthly demand and supply for the Verde River is indicated in Figure 8 with the modified HA values reflected in Figures 8 and 9. Scenario 2 sees a slightly higher fill rate on the river and less impact to median flow in June.

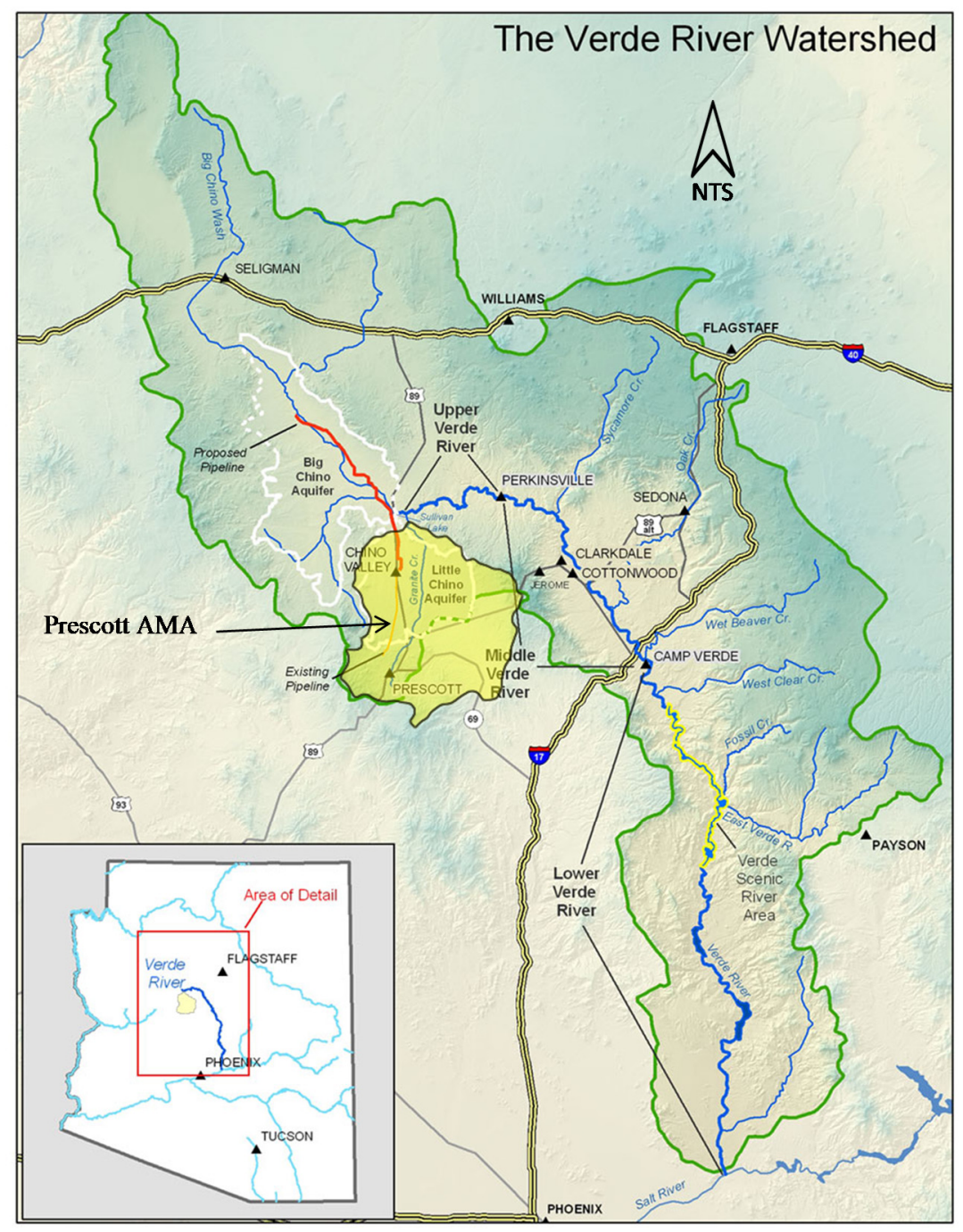

Figure 4. Verde watershed and relative location of the Prescott AMA 


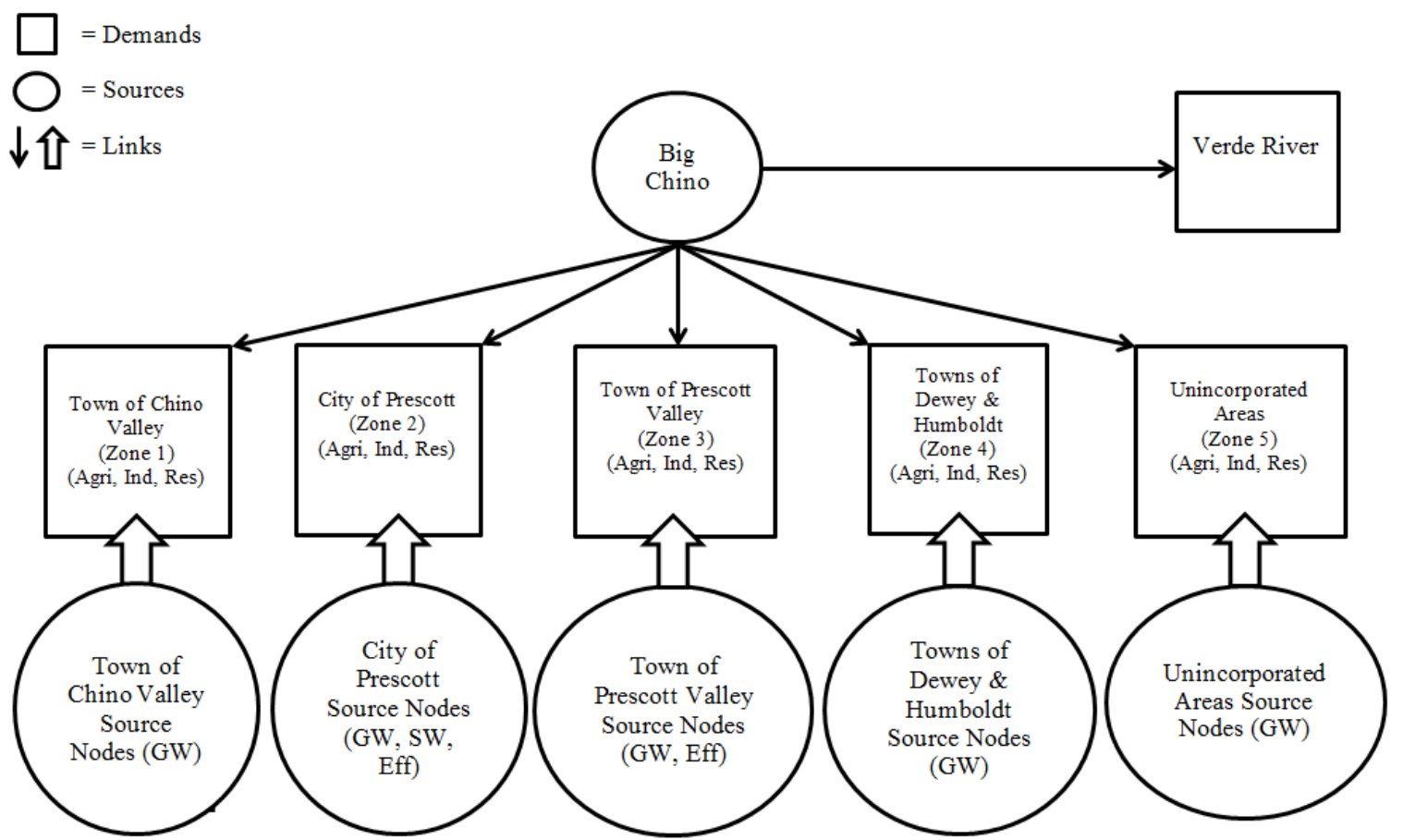

Figure 5. Schematic of the Prescott AMA

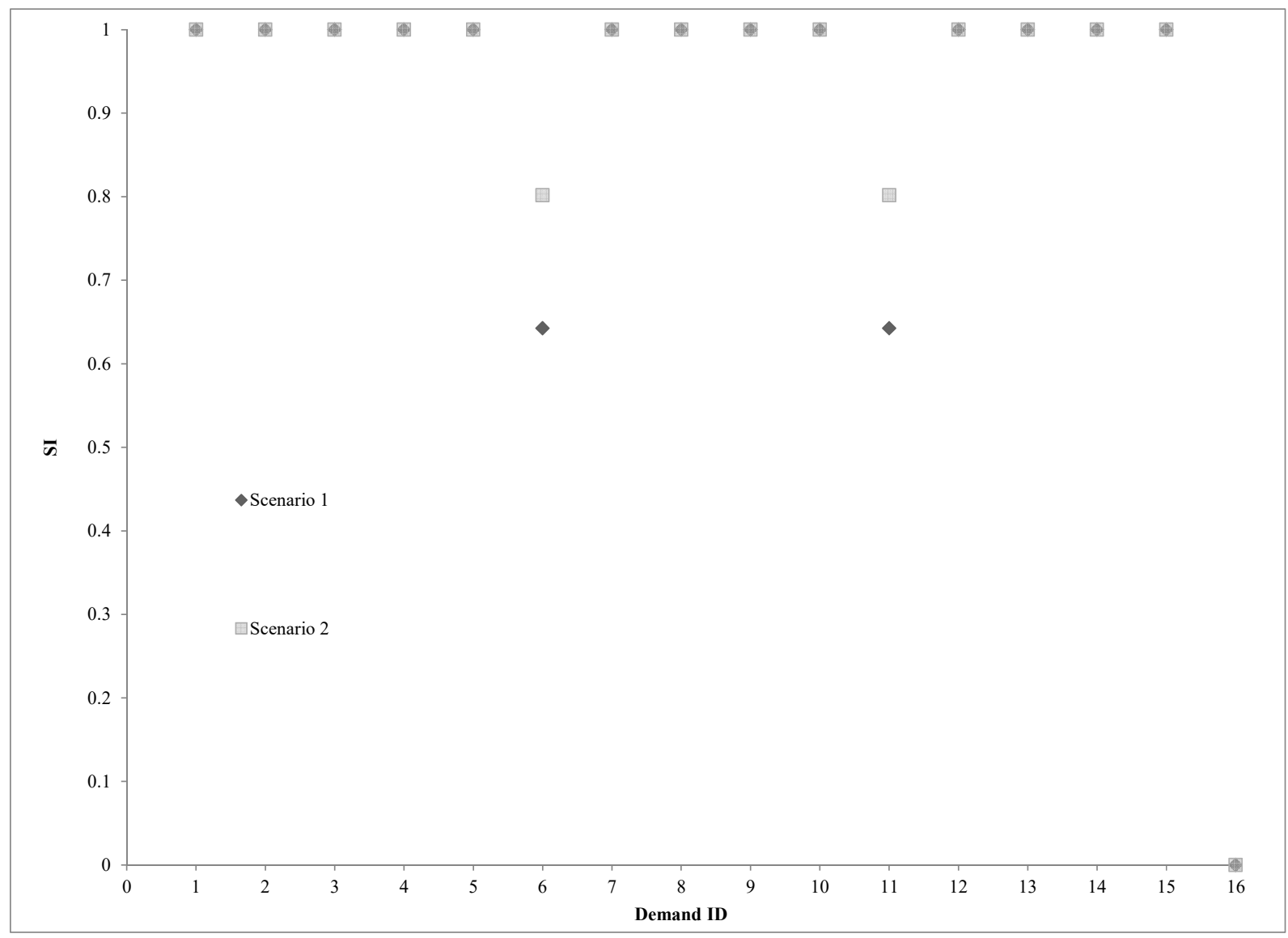

Figure 6. Demand-supply deficit based SI values for each of the demand nodes for the Prescott AMA scenarios 


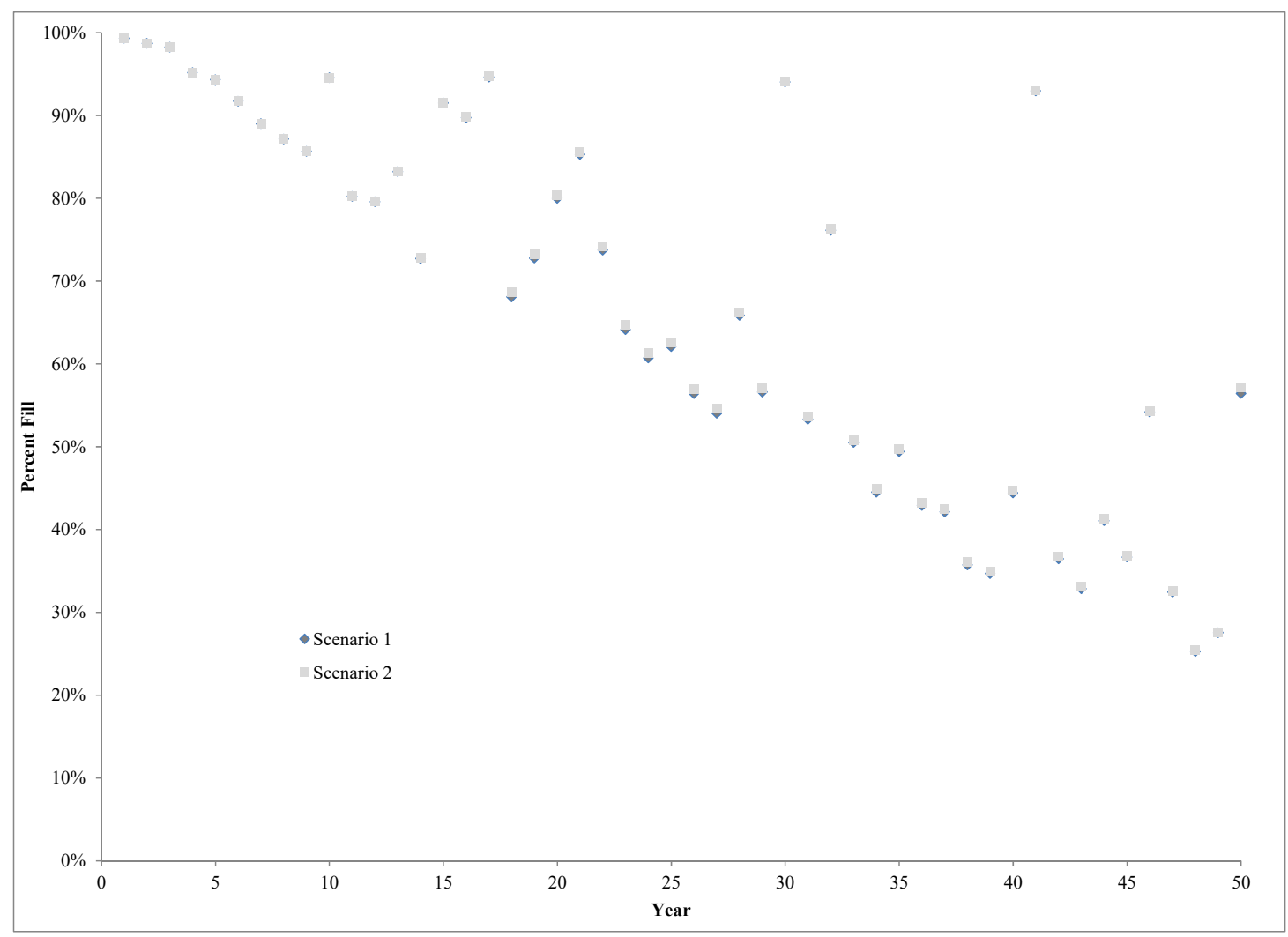

Figure 7. Ratio of annual supply to demand on the Verde River in percent

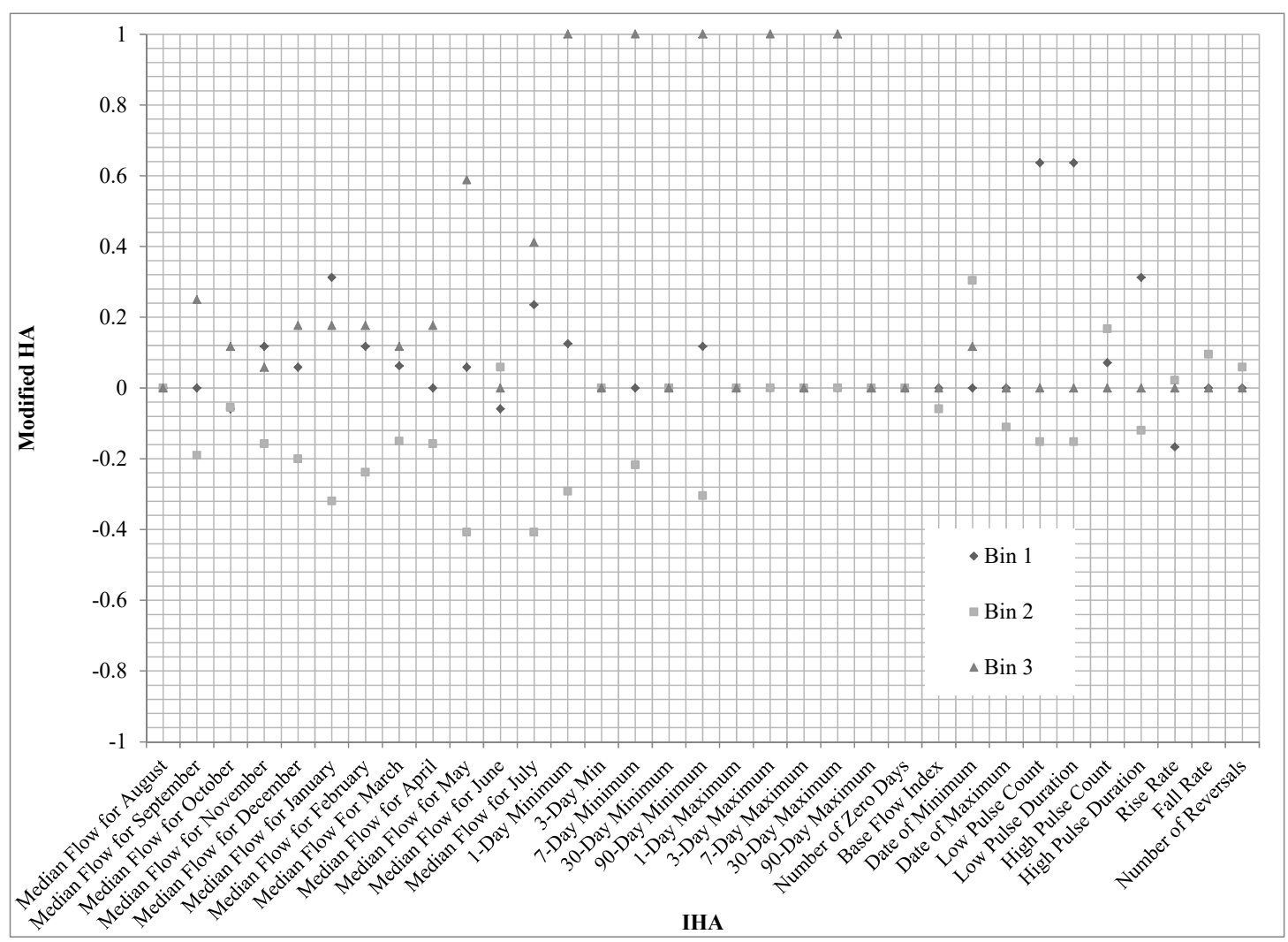

Figure 8. Modified HA values for Scenario 1. 


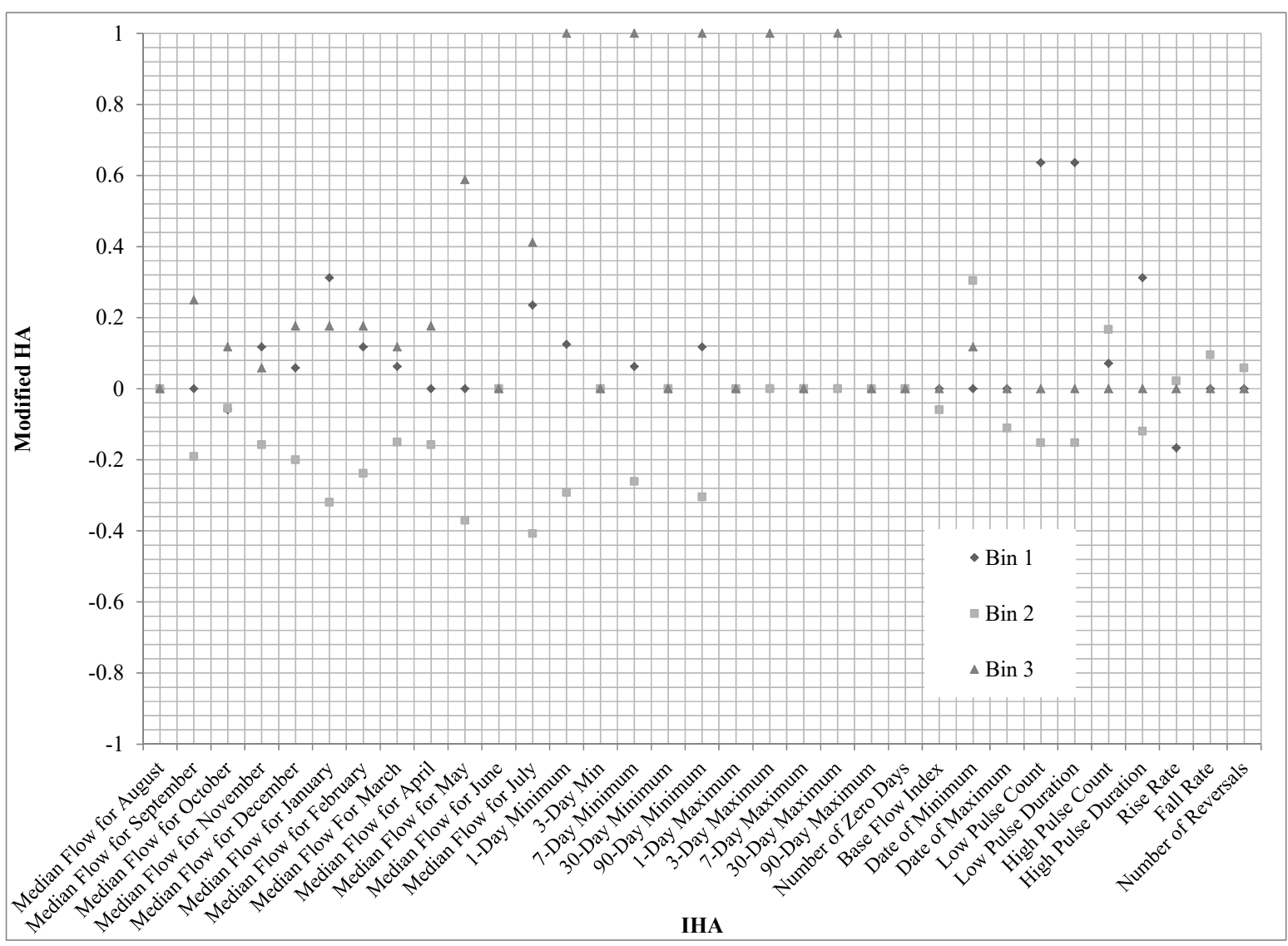

Figure 9. Modified HA values for Scenario 2

Table 3. Residential population growth rates for the Prescott AMA scenarios.

\begin{tabular}{|c|c|c|c|c|c|}
\hline \multirow[b]{2}{*}{ Scenario } & \multicolumn{5}{|c|}{ Demand } \\
\hline & $\begin{array}{c}\text { Zone } 1 \text { - Town of } \\
\text { Chino Valley }\end{array}$ & $\begin{array}{c}\text { Zone 2- City of } \\
\text { Prescott }\end{array}$ & $\begin{array}{c}\text { Zone } 3 \text { - Town of } \\
\text { Prescott Valley }\end{array}$ & $\begin{array}{l}\text { Zone } 4 \text { - Towns of } \\
\text { Dewey/Humboldt }\end{array}$ & $\begin{array}{c}\text { Zone } 5 \text { - } \\
\text { Unincorporated areas }\end{array}$ \\
\hline 1 & $-0.5 \%$ & $0.6 \%$ & $1.8 \%$ & $1.6 \%$ & $1.1 \%$ \\
\hline 2 & $-0.4 \%$ & $0.1 \%$ & $1.4 \%$ & $1.3 \%$ & $0.9 \%$ \\
\hline
\end{tabular}

Table 4. Residential consumption rates for the Prescott AMA scenarios.

\begin{tabular}{cccccc}
\hline & \multicolumn{5}{c}{ Demand } \\
\cline { 2 - 6 } Scenario & $\begin{array}{c}\text { Zone 1 - Town of } \\
\text { Chino Valley }\end{array}$ & $\begin{array}{c}\text { Zone 2- City of } \\
\text { Prescott }\end{array}$ & $\begin{array}{c}\text { Zone 3 - Town of } \\
\text { Prescott Valley }\end{array}$ & $\begin{array}{c}\text { Zone 4 - Towns of } \\
\text { Dewey/Humboldt }\end{array}$ & $\begin{array}{c}\text { Zone 5 - } \\
\text { Unincorporated areas }\end{array}$ \\
\cline { 2 - 6 } & $\begin{array}{c}{[\text { Ac-ft }} \\
\text { month/consumer }]\end{array}$ & $\begin{array}{c}{[\text { Ac-ft }} \\
\text { month/consumer }]\end{array}$ & $\begin{array}{c}{[\text { Ac-ft }} \\
\text { month/consumer }]\end{array}$ & $\begin{array}{c}{[\text { Ac-ft }} \\
\text { month/consumer }]\end{array}$ & $\begin{array}{c}{[\text { Ac-ft }} \\
\text { month/consumer }]\end{array}$ \\
\hline \multirow{2}{*}{1} & $8.446 \mathrm{E}-03$ & $8.654 \mathrm{E}-03$ & $9.572 \mathrm{E}-03$ & $9.582 \mathrm{E}-03$ & $9.228 \mathrm{E}-03$ \\
2 & $8.386 \mathrm{E}-03$ & $8.108 \mathrm{E}-03$ & $9.418 \mathrm{E}-03$ & $9.168 \mathrm{E}-03$ & $8.324 \mathrm{E}-03$ \\
\hline
\end{tabular}


Table 5. Demand nodes for the Prescott AMA simulation

\begin{tabular}{cl}
\hline $\begin{array}{c}\text { Demand } \\
\text { Node }\end{array}$ & \multicolumn{1}{c}{ Label } \\
\hline 1 & Zone 1 - Town of Chino Valley \\
2 & Zone 2 - City of Prescott \\
3 & Zone 3 - Town of Prescott Valley \\
4 & Zone 4 - Towns of Dewey/Humboldt \\
5 & Zone 5 - Unincorporated areas \\
6 & Zone 1 - Agri \\
7 & Zone 2 - Agri \\
8 & Zone 3 - Agri \\
9 & Zone 4 - Agri \\
10 & Zone 5 - Agri \\
11 & Zone 1 - Industrial \\
12 & Zone 2 - Industrial \\
13 & Zone 3 - Industrial \\
14 & Zone 4 - Industrial \\
15 & Zone 5 - Industrial \\
16 & Verde River \\
\hline
\end{tabular}

Table 6. Source nodes for the Prescott AMA simulation

\begin{tabular}{cl}
\hline $\begin{array}{c}\text { Source } \\
\text { Node }\end{array}$ & \multicolumn{1}{c}{ Label } \\
\hline 1 & Big Chino Water Ranch \\
2 & Zone 2 - Ground Water \\
3 & Zone 3 - Ground Water \\
4 & Zone 4 - Ground Water \\
5 & Zone 5 - Ground Water \\
6 & Zone 2 - Surface water \\
7 & Zone 2 - Effluent \\
8 & Zone 3 - Effluent \\
9 & Big Chino River Source \\
\hline
\end{tabular}

Table 7. SS values for the Prescott AMA scenarios

\begin{tabular}{cc}
\hline Scenario & SS \\
\hline 1 & $8.4029 \mathrm{E}-01$ \\
2 & $8.5906 \mathrm{E}-01$ \\
\hline
\end{tabular}

\section{Conclusions}

Sustainability in this research is defined in terms of minimizing the long-term risks to supply and maintaining the ecological, environmental and hydrological integrity of a river resource. It is measured using a sustainability index comprised of two groups of performance criteria. The first group of performance criteria is based on demandsupply deficits and provides metrics for the risk to water supplies. The second group addresses the integrity of a flow regime using the RVA and Modified HA to compare a projected flow regime to a target flow regime. Sustainability for the entire system is determined using the weighted sum of the sustainability indices. The framework has been-applied to measure and compare the sustainability of two allocation scenarios for the Prescott AMA. This framework has applicability to other river basins that have the required input data.

\section{References}

Alcamo, J., FlöRke, M., \& MäRker, M. (2007). Future long-term changes in global water resources driven by socio-economic and climatic changes. Hydrological Sciences Journal, 52(2), 247-275. 
Arizona Department of Water Resources. (n.d.). Overview of the Arizona Groundwater Management Code.

Arthington, A. H., Bunn, S. E., Poff, N. L., \& Naiman, R. J. (2006). The challenge of providing environmental flow rules to sustain river ecosystems. Ecological App, 16(4), 1311-1318.

Aydin, A. Y., Mays, L. W., \& Schmitt, T. (2014a), Sustainability Assessment for Urban Water Distribution Systems, Water Resources Management (pp. 4373-4384). https://doi.org/10.1007/s11269-014-07757-1.

Aydin, A. Y., Mays, L. W., \& Schmitt, T. (2014b), Technical and Environmental Sustainability Assessment of Water Distribution Systems, Water Resources Management. https://doi.org/10.1007/s11269-014-0768-y

Cai, X. (1999). A modeling framework for sustainable water resources management. Doc, University of Texas at Austin, Austin, TX.

Cai, X., McKinney, D. C., \& Lasdon, L. S. (2003). Integrated Hydrologic-Agronomic-Economic Model for River Basin Management. Journal of Water Resources Planning and Management, 129(1), 4.

Gleick, P. H. (2000). A Look at Twenty-first Century Water Resources Development. Water International, 25(1), 127-138.

Kuhlman, T., \& Farrington, J. (2010). What is Sustainability? Sustainability, 2(11), 3436-3448.

Lant, C. (2007). Water resources sustainability: an ecological-economics perspective. In L. W. Mays (ed.), Water resources sustainability. McGraw-Hill; WEF Press, New York : Alexandria, Va.

Loucks, D. P. (1997). Quantifying trends in system sustainability. Hydrological Sciences Journal, 42(4), 513-530.

Loucks, D. P., \& Gladwell, J. S. (1999). International Hydrological Programme, and Unesco/IHP-IV Project M4.3. Sustainablity criteria for water resource systems. Cambridge University Press, New York.

Mays, L. W. (Ed.). (2007). Water resources sustainability. McGraw-Hill ; WEF Press, New York: Alexandria, Va.

Mays, L.W. (2013). Groundwater Resources Sustainability: Past, Present, and Future. Water Resources Management, 27(13), 4409-4424.

Oxley, R. L. (2015). Ecological, environmental and hydrological integrity in sustainable water resource management for river basins. Doctoral Dissertation, Arizona State University.

Oxley, R. L., Mays, L. W., \& Murray, A. (2016). Optimization Model for the Sustainable Water Resource Management of River Basins. Water Resources Management. https://doi.org/10.1007/s11269-016-1345-3.

Oxley, R. L., \& Mays, L. W. (2016). Application of an Optimization Model for the Sustainable Water Resource Management of River Basins, Water Resources Management. https://doi.org/10.1007/s11269-016-1459-7

Poff, N. L. (2009). Managing for Variability to Sustain Freshwater Ecosystems. Journal of Water Resources Planning and Management, 135(1), 1.

Poff, N. L., Allan, J. D., Bain, M. B., Karr, J. R., Prestegaard, K. L., Richter, B. D., Sparks, R. E., \& Stromberg, J. C. (1997). The Natural Flow Regime. BioScience, 47(11), 769.

Pool, D. R., Blasch, K. W., Callegary, J. B., Leake, S. A., \& Graser, L. F. (2011). Regional groundwater-flow model of the Redwall-Muav, Coconino, and alluvial basin aquifer systems of northern and central Arizona: U.S. Geological Survey.

Richter, B., Baumgartner, J., Wigington, R., \& Braun, D. (1997). How much water does a river need? Freshwater Biology, 37(1), 231-249.

Rijsberman, F. R. (2006). Water scarcity: Fact or fiction? Agricultural Water Management, 80(1-3), 5-22.

Rosegrant, M. W., Cai, X., Cline, S. A., International Food Policy Research Institute., and International Water Management Institute. (2002). Global water outlook to 2025 averting an impending crisis. International Food Policy Research Institute, Washington, D.C.

Rothman, D. W. (2007). Evaluation of water resources sustainability using a multi-objective genetic algorithm. Doctoral Dissertation, Arizona State University.

Rothman, D. W., \& Mays, L. W. (2014). Water Resources Sustainability: Development of a Multi-Objective Optimization Model. Journal of Water Resources Planning and Management, 131126205031004.

Sandoval-Solis, S., McKinney, D. C., \& Loucks, D. P. (2011). Sustainability Index for Water Resources Planning and Management. Journal of Water Resources Planning and Management, 137(5), 381. 
Slottje, D. (1991). Measuring the quality of life across countries. The Review of Economics and Statistics, 73(4), 684-693.

Solow, R. M. (1993). Sustainability: an economist's perspective. In R. Dorfman, \& N. Dorfman (eds.), Economics of the Environment: Selected Readings (pp. 179-187). Norton and Company.

Tharme, R. E. (2003). A global perspective on environmental flow assessment: emerging trends in the development and application of environmental flow methodologies for rivers. River Research and Applications, 19(5-6), 397-441.

The Nature Conservancy. (2009). Indicators of hydrologic alteration version 7.1 user's manual.

Unver, O. (2007). Water-based sustainable integrated regional development. In L. W. Mays (ed.), Water resources sustainability. McGraw-Hill ; WEF Press, New York : Alexandria, Va..

U.S. Census Bureau. (2010). Cities Totals: All Incorporated Places: 2000 to 2009 - U.S Census Bureau. Cesnsus.gov,

Vorosmarty, C. J. (2000). Global Water Resources: Vulnerability from Climate Change and Population Growth. Science, 289(5477), 284-288.

World Commission on Environment and Development. (1987). Our common future. Oxford University Press, Oxford; New York.

\section{Copyrights}

Copyright for this article is retained by the author(s), with first publication rights granted to the journal.

This is an open-access article distributed under the terms and conditions of the Creative Commons Attribution license (http://creativecommons.org/licenses/by/4.0/). 